Bažant, Z.P., and Chern, J.-C. (1985). "Triple power law for concrete creep." J. of Engrg. Mechanics, ASCE 111, 63-83.

\title{
Triple Power law for Concrete Creep
}

\author{
By Zdeněk P. Bažant, ${ }^{1}$ F. ASCE and Jenn-Chuan Chern ${ }^{2}$
}

\begin{abstract}
An improved creep law for concrete at constant temperature and water content is proposed. It gives the creep rate as a product of power functions of the load duration, the age at loading and the current age of concrete. This law exhibits a gradual smooth transition from the double power law for very short load durations to the logarithmic law for very long load durations. The higher the age at loading, the longer the load duration at the transition. Determination of creep compliance requires evaluation of a binomial integral, which can be carried out either with the help of a truncated power series or by replacement of certain integrals with sums. A table of values from which interpolation is possible is also given. Extensive fitting of creep data from the literature reveals only a modest improvement in the overall coefficient of variation of the deviations from test data; however, the terminal slopes of creep curves are significantly improved, which is especially important for extrapolation of creep measurements. Compared to the previous double power-logarithmic law, the present formulation has an advantage of continuity in curvature, and compared to the log-double power law, the present formulation has a greater range of applicability involving also very short creep durations, including the dynamic range. The new formulation also significantly limits the occurrence of divergence of creep curves, and permits even a complete suppression of this property, although at the cost of a distinct impairment in data fits.
\end{abstract}

\section{INTRODUCTION}

The compliance function for concrete creep may be relatively well-expressed as a power function of the load duration times another power function of the age at loading. Extensive statistical studies of the bulk of the test data that exist in the literature have revealed a much better agreement than that attainable with other creep formulas previously proposed. However, as has been pointed out recently $(9,10)$, comparisons with test data reveal certain deviations which appear to be systematic rather than random. The slope of the creep curves at constant age at loading, plotted in log-time scale, appears to be too high in comparison with observations when the load duration is long. This paper shows that this deficiency can be remedied by a particular form of the triple power law recently proposed on the basis of a micromechanics investigation (2). The present formulation also has certain advantages over two previous attempts to eliminate the same shortcoming $(3,4)$.

\section{Review of Some Previous Creep laws}

For most situations within the service stress range of structures, concrete creep at constant temperature and water content can be assumed

${ }^{1}$ Prof. of Civ. Engrg. and Dir., Center for Concrete and Geomaterials, The Technological Inst., Northwestern Univ., Evanston, IIl. 60201.

${ }^{2}$ Grad. Research Asst., Northwestern Univ.; presently Postdoctoral Research Assoc., Div. of Reactor Analysis and Safety, Argonne National Lab., Argonne, Ill. 60439 .

Note.-Discussion open until June 1, 1985. To extend the closing date one month, a written request must be filed with the ASCE Manager of Journals. The manuscript for this paper was submitted for review and possible publication on February 22, 1984. This paper is part of the Joumal of Engineering Mechanics, Vol. 111, No. 1, January, 1985. CASCE, ISSN 0733-9399/85/0001-0063/\$01.00. Paper No. 19397. 

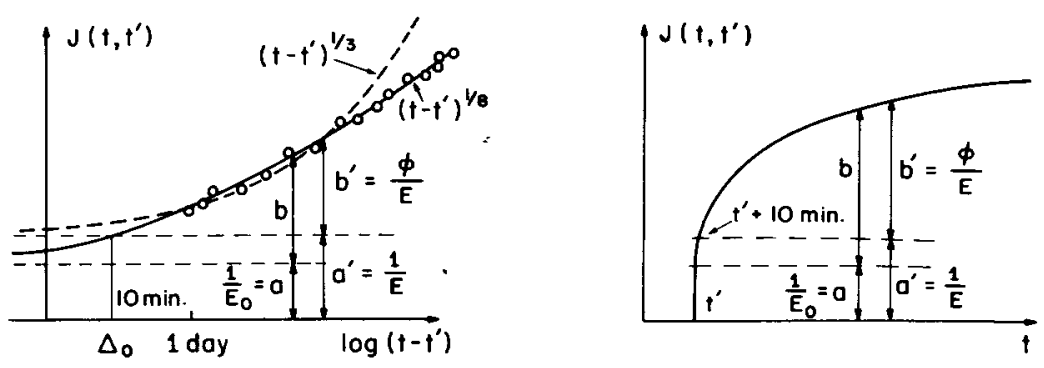

FIG. 1.-Creep Curves in Logarithmic $t-t^{\prime}$ and Normal $t$ Scales $(a=$ True Elastic Deformation, $b=$ True Creep, $a^{\prime}=$ Conventional Elastic Deformation, $b^{\prime}=$ Conventional Creep)

to be linear, following the principle of superposition. It may then be completely characterized by the compliance function $J\left(t, t^{\prime}\right)$, also called the creep function, which represents the strain (elastic + creep) at age $t$ caused by a uniaxial constant stress acting since age $t^{\prime}$. According to the double power law $(1,6,10)$, the compliance function is expressed as

$J\left(t, t^{\prime}\right)=\frac{1}{E_{0}}+\frac{\phi_{1}}{E_{0}}\left(t^{\prime-m}+\alpha\right)\left(t-t^{\prime}\right)^{n}$

in which $E_{0}=$ asymptotic modulus, such that $1 / E_{0}$ represents the asymptotic value of the creep curve $J\left(t, t^{\prime}\right)$ versus $\log \left(t-t^{\prime}\right)$ as $\log \left(t-t^{\prime}\right) \rightarrow$ $-\infty$ or $\left(t-t^{\prime}\right) \rightarrow 0 ; n, m, \alpha$ and $\phi_{1}$ are material parameters whose typical values are $n \simeq 1 / 8, m \simeq 1 / 3, \phi_{1}=3$ to 6 ; and if $t$ and $t^{\prime}$ are in days $\alpha$ $\simeq 0.05 ; E_{0} \simeq 1.5 E_{28}$ where $E_{28}=$ conventional (static) elastic modulus at an age of 28 days. Since $\left(t-t^{\prime}\right)^{n}=\exp \left[n \ln \left(t-t^{\prime}\right)\right]$, the plots of $J\left(t, t^{\prime}\right)$ versus $\log \left(t, t^{\prime}\right)$ at constant $t^{\prime}$ have the shape of exponentials.

Compared with most long-term test data, the slope of the power curves of load duration $t-t^{\prime}$ appears to be too high for very long load durations. From measurements it appears that the slope of the creep curves plotted in the scale of $\log \left(t-t^{\prime}\right)$ appears to reach a certain constant asymptotic value for sufficiently long load durations (Fig. 1). The slope appears to be the same for all ages at loading. This behavior was described in a previous study by a two-part formula that exhibits a transition to a straight line in the logarithmic scale of load duration (4). In that study, this transition was assumed to occur suddenly at a certain transition time which increases with the age at loading. In a subsequent study (3), a single formula for which the transition from the power function to the logarithmic function is gradual, without a discontinuous jump in curvature, was proposed. This formula is, however, more complicated, and is not applicable to very short load durations, unlike the double power law. This paper shows that, if one accepts as the basis of modeling the creep rate rather than the total strain values, one can attain all the objectives of the previous studies with a simpler and more general formula.

Aside from simplicity, modeling of creep on the basis of the creep rate rather than the total strain has advantages from the viewpoint of physical interpretation and micromechanics arguments. Expressions for the creep rate can be deduced from the activation energy theory (rate-process theory) $(26,27)$, and also arise from stochastic process modeling of creep (15), as well as from certain composite material models for concrete (2)

\section{Triple Power Law for Creep Rate}

It will be shown that a smooth transition between the double power law for short load durations and a logarithmic law for long load durations may be achieved by the following formula for the unit creep rate:

$$
\dot{J}\left(t, t^{\prime}\right)=\frac{\psi_{1}}{E_{0}} \frac{t^{\prime^{-m}}+\alpha}{\left(t-t^{\prime}\right)^{1-n}\left(\frac{t}{t^{\prime}}\right)^{n}}
$$

in which $J\left(t, t^{\prime}\right)=\partial J\left(t, t^{\prime}\right) / \partial t=$ compliance rate $=$ unit creep rate; and $E_{0}, \psi_{1}, n, m$ and $\alpha$ are five material parameters, similar but not identical to those in the double power law. We will call Eq. 2 the triple power law since three power functions, namely those of $t-t^{\prime}, t^{\prime}$ and $t / t^{\prime}$, are involved. For $\alpha=0$, Eq. 2 becomes identical to a formula proposed before on the basis of a micromechanics analysis of a solidifying material (Eq. 22 of Ref. 2)

For very short load durations, $t-t^{\prime}<<t^{\prime}$, the value of $t / t^{\prime}$ is nearly 1, and so Eq. 2 becomes

$\dot{J}\left(t, t^{\prime}\right) \simeq \frac{\psi_{1}}{E_{0}} \frac{t^{\prime-m}+\alpha}{\left(t-t^{\prime}\right)^{1-n}}$

Setting $\psi_{1}=n \phi_{1}$, Eq. 3 is identical to the derivative of the double power law (Eq. 1). For very long load durations, $t-t^{\prime}>t^{\prime}$, we may approximately replace $t-t^{\prime}$ with $t$ in Eq. 2, and thus we obtain

$\dot{J}\left(t, t^{\prime}\right)=\frac{\psi_{1}}{E_{0}}\left(t^{\prime-m}+\alpha\right) t^{\prime \prime} \frac{1}{t}\left(t-t^{\prime}>>t^{\prime}\right)$.

(a)
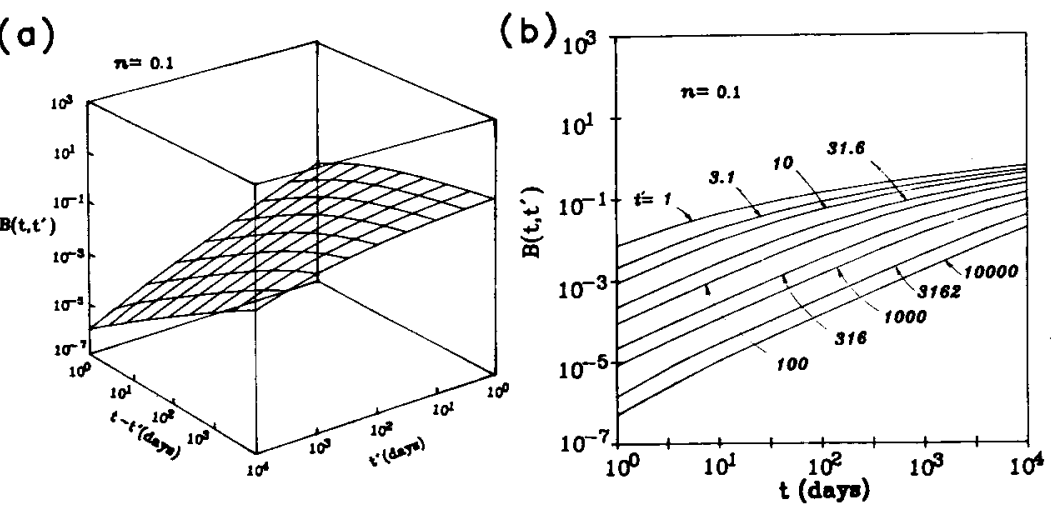

FIG. 2-Two- and Three-Dimensional Graphs of Binomial Integral $B\left(t, t^{\prime} ; n\right)$ 
TABLE 1.-Binomia

\begin{tabular}{|c|c|c|c|c|c|}
\hline $\begin{array}{c}n \\
(1)\end{array}$ & $\begin{array}{c}t^{\prime} \\
(2)\end{array}$ & $\begin{array}{c}1 \\
(3) \\
\end{array}$ & $\begin{array}{c}\sqrt{10} \\
(4)\end{array}$ & $\begin{array}{r}10 \\
(5)\end{array}$ & $\begin{array}{c}\sqrt{100} \\
(6)\end{array}$ \\
\hline 0.06 & $\begin{array}{r}1 \\
\sqrt{10} \\
10 \\
\sqrt{100} \\
100 \\
\sqrt{1,000} \\
1,000 \\
\sqrt{10,000} \\
10,000\end{array}$ & $\begin{array}{l}0.00274 \\
0.000986 \\
0.000324 \\
0.000099 \\
0.000026 \\
0 \\
0 \\
0 \\
0\end{array}$ & $\begin{array}{l}0.00705 \\
0.00293 \\
0.00106 \\
0.000347 \\
0.000107 \\
0.000028 \\
0 \\
0 \\
0\end{array}$ & $\begin{array}{l}0.0153 \\
0.00755 \\
0.00314 \\
0.00113 \\
0.000372 \\
0.000114 \\
0.000030 \\
0 \\
0\end{array}$ & $\begin{array}{l}0.0286 \\
0.0164 \\
0.00809 \\
0.00337 \\
0.00121 \\
0.000399 \\
0.000122 \\
0.000033 \\
0\end{array}$ \\
\hline 0.10 & $\begin{array}{r}1 \\
\sqrt{10} \\
10 \\
\sqrt{100} \\
100 \\
\sqrt{1,000} \\
1,000 \\
\sqrt{10,000} \\
10,000\end{array}$ & $\begin{array}{l}0.00725 \\
0.00263 \\
0.000869 \\
0.000268 \\
0.000073 \\
0 \\
0 \\
0 \\
0\end{array}$ & $\begin{array}{l}0.0193 \\
0.00814 \\
0.00295 \\
0.00975 \\
0.000301 \\
0.000081 \\
0 \\
0 \\
0\end{array}$ & $\begin{array}{l}0.0430 \\
0.0216 \\
0.00913 \\
0.00331 \\
0.00109 \\
0.000338 \\
0.000091 \\
0 \\
0\end{array}$ & $\begin{array}{l}0.0821 \\
0.0483 \\
0.0243 \\
0.0102 \\
0.00372 \\
0.00123 \\
0.000379 \\
0.000102 \\
0\end{array}$ \\
\hline 0.15 & $\begin{array}{r}1 \\
\sqrt{10} \\
10 \\
\sqrt{100} \\
100 \\
\sqrt{1,000} \\
1,000 \\
\sqrt{10,000} \\
10,000\end{array}$ & $\begin{array}{l}0.0154 \\
0.00564 \\
0.00187 \\
0.000583 \\
0.000160 \\
0 \\
0 \\
0 \\
0\end{array}$ & $\begin{array}{l}0.0426 \\
0.0183 \\
0.00671 \\
0.00223 \\
0.000693 \\
0.000190 \\
0 \\
0 \\
0\end{array}$ & $\begin{array}{l}0.0983 \\
0.0507 \\
0.0217 \\
0.00797 \\
0.00265 \\
0.000823 \\
0.000226 \\
0 \\
0\end{array}$ & $\begin{array}{l}0.193 \\
0.117 \\
0.0602 \\
0.0258 \\
0.00947 \\
0.00315 \\
0.000978 \\
0.000269 \\
0\end{array}$ \\
\hline 0.20 & $\begin{array}{r}1 \\
\sqrt{10} \\
10 \\
\sqrt{100} \\
100 \\
\sqrt{1,000} \\
1,000 \\
\sqrt{10,000} \\
10,000\end{array}$ & $\begin{array}{l}0.0259 \\
0.00957 \\
0.00320 \\
0.00100 \\
0.000279 \\
0 \\
0 \\
0 \\
0\end{array}$ & $\begin{array}{l}0.0746 \\
0.0326 \\
0.0120 \\
0.00402 \\
0.00126 \\
0.000352 \\
0 \\
0 \\
0\end{array}$ & $\begin{array}{l}0.178 \\
0.0940 \\
0.0410 \\
0.0152 \\
0.00506 \\
0.00159 \\
0.00443 \\
0 \\
0\end{array}$ & $\begin{array}{l}0.361 \\
0.224 \\
0.118 \\
0.0516 \\
0.0191 \\
0.00638 \\
0.00200 \\
0.000557 \\
0\end{array}$ \\
\hline 0.25 & $\begin{array}{r}1 \\
\sqrt{10} \\
10 \\
\sqrt{100} \\
100 \\
\sqrt{1,000} \\
1,000 \\
\sqrt{10,000} \\
10,000\end{array}$ & $\begin{array}{l}0.0383 \\
0.0143 \\
0.00479 \\
0.00151 \\
0.00428 \\
0 \\
0 \\
0 \\
0\end{array}$ & $\begin{array}{l}0.115 \\
0.051 \\
0.019 \\
0.00639 \\
0.00201 \\
0.00571 \\
0 \\
0 \\
0\end{array}$ & $\begin{array}{l}0.284 \\
0.153 \\
0.0680 \\
0.0254 \\
0.00853 \\
0.00269 \\
0.000761 \\
0 \\
0\end{array}$ & $\begin{array}{l}0.593 \\
0.379 \\
0.205 \\
0.0907 \\
0.0339 \\
0.0114 \\
0.00358 \\
0.00101 \\
0\end{array}$ \\
\hline
\end{tabular}

Integral $B\left(t, t^{\prime} ; n\right)$

\begin{tabular}{|c|c|c|c|c|}
\hline \multicolumn{5}{|l|}{$t-t^{\prime}$} \\
\hline $\begin{array}{l}100 \\
(7)\end{array}$ & $\begin{array}{c}\sqrt{1,000} \\
(8)\end{array}$ & $\begin{array}{c}1,000 \\
(9)\end{array}$ & $\begin{array}{c}\sqrt{10,000} \\
(10)\end{array}$ & $\begin{array}{c}10,000 \\
(11)\end{array}$ \\
\hline $\begin{array}{l}0.0476 \\
0.0306 \\
0.0176 \\
0.00867 \\
0.00361 \\
0.00130 \\
0.000427 \\
0.000131 \\
0.000035 \\
\end{array}$ & $\begin{array}{l}0.0728 \\
0.0510 \\
0.0328 \\
0.0188 \\
0.00929 \\
0.00387 \\
0.00139 \\
0.000458 \\
0.000141 \\
\end{array}$ & $\begin{array}{l}0.105 \\
0.078 \\
0.0546 \\
0.0352 \\
0.0202 \\
0.00996 \\
0.00414 \\
0.00149 \\
0.000491 \\
\end{array}$ & $\begin{array}{l}0.144 \\
0.122 \\
0.0836 \\
0.0585 \\
0.0377 \\
0.0216 \\
0.0107 \\
0.00444 \\
0.00160 \\
\end{array}$ & $\begin{array}{l}0.191 \\
0.154 \\
0.120 \\
0.0895 \\
0.0627 \\
0.0404 \\
0.0232 \\
0.0114 \\
0.00476 \\
\end{array}$ \\
\hline $\begin{array}{l}0.140 \\
0.0922 \\
0.0541 \\
0.0272 \\
0.0115 \\
0.00417 \\
0.00138 \\
0.000425 \\
0.000115 \\
\end{array}$ & $\begin{array}{l}0.218 \\
0.157 \\
0.103 \\
0.0607 \\
0.0306 \\
0.0129 \\
0.00468 \\
0.00155 \\
0.000477 \\
\end{array}$ & $\begin{array}{l}0.320 \\
0.244 \\
0.176 \\
0.116 \\
0.0682 \\
0.0343 \\
0.0145 \\
0.00525 \\
0.00173 \\
\end{array}$ & $\begin{array}{l}0.448 \\
0.359 \\
0.274 \\
0.197 \\
0.130 \\
0.0765 \\
0.0385 \\
0.0162 \\
0.00589 \\
\end{array}$ & $\begin{array}{l}0.606 \\
0.503 \\
0.403 \\
0.308 \\
0.221 \\
0.146 \\
0.0858 \\
0.0432 \\
0.0181 \\
\end{array}$ \\
\hline $\begin{array}{l}0.338 \\
0.230 \\
0.139 \\
0.0716 \\
0.0307 \\
0.0113 \\
0.00374 \\
0.00116 \\
0.000320\end{array}$ & $\begin{array}{l}0.541 \\
0.401 \\
0.273 \\
0.165 \\
0.0851 \\
0.0365 \\
0.0134 \\
0.00444 \\
0.00138\end{array}$ & $\begin{array}{l}0.816 \\
0.643 \\
0.477 \\
0.325 \\
0.196 \\
0.101 \\
0.0434 \\
0.0159 \\
0.00528\end{array}$ & $\begin{array}{l}1.17 \\
0.969 \\
0.764 \\
0.567 \\
0.386 \\
0.233 \\
0.120 \\
0.0516 \\
0.0189\end{array}$ & $\begin{array}{l}1.63 \\
1.40 \\
1.15 \\
0.909 \\
0.674 \\
0.459 \\
0.277 \\
0.143 \\
0.0613\end{array}$ \\
\hline $\begin{array}{l}0.648 \\
0.454 \\
0.282 \\
0.149 \\
0.0650 \\
0.0240 \\
0.00803 \\
0.00251 \\
0.000701 \\
\end{array}$ & $\begin{array}{l}1.07 \\
0.816 \\
0.572 \\
0.355 \\
0.187 \\
0.0818 \\
0.0303 \\
0.0101 \\
0.00316 \\
\end{array}$ & $\begin{array}{l}1.66 \\
1.34 \\
1.03 \\
0.720 \\
0.447 \\
0.236 \\
0.103 \\
0.0381 \\
0.0127 \\
\end{array}$ & $\begin{array}{l}2.46 \\
2.09 \\
1.69 \\
1.29 \\
0.906 \\
0.563 \\
0.297 \\
0.130 \\
0.0480 \\
\end{array}$ & $\begin{array}{l}3.52 \\
3.09 \\
2.63 \\
2.13 \\
1.63 \\
1.14 \\
0.709 \\
0.374 \\
0.163 \\
\end{array}$ \\
\hline $\begin{array}{l}1.10 \\
0.791 \\
0.505 \\
0.273 \\
0.121 \\
0.0452 \\
0.0152 \\
0.00478 \\
0.00135 \\
\end{array}$ & $\begin{array}{l}1.86 \\
1.46 \\
1.05 \\
0.673 \\
0.363 \\
0.161 \\
0.0602 \\
0.0202 \\
0.00637\end{array}$ & $\begin{array}{l}2.98 \\
2.49 \\
1.95 \\
1.41 \\
0.898 \\
0.485 \\
0.215 \\
0.0803 \\
0.0270\end{array}$ & $\begin{array}{l}4.57 \\
3.98 \\
3.32 \\
2.60 \\
1.88 \\
1.20 \\
0.647 \\
0.287 \\
0.107\end{array}$ & $\begin{array}{l}6.78 \\
6.10 \\
5.31 \\
4.42 \\
3.47 \\
2.50 \\
1.60 \\
0.862 \\
0.383\end{array}$ \\
\hline
\end{tabular}


TABLE 1.-

\begin{tabular}{c|r|l|l|l|l}
\hline (1) & \multicolumn{1}{|c|}{$(2)$} & \multicolumn{1}{c|}{$(3)$} & \multicolumn{1}{c|}{$(4)$} & \multicolumn{1}{c}{$(5)$} & \multicolumn{1}{c}{$(6)$} \\
\hline 0.30 & 1 & 0.0522 & 0.164 & 0.418 & 0.902 \\
& $\sqrt{10}$ & 0.0197 & 0.0738 & 0.231 & 0.591 \\
& 10 & 0.00664 & 0.0278 & 0.104 & 0.326 \\
& $\sqrt{100}$ & 0.00210 & 0.00938 & 0.0392 & 0.147 \\
& 100 & 0.000604 & 0.00297 & 0.0132 & 0.0554 \\
& $\sqrt{1,000}$ & 0 & 0.00853 & 0.00419 & 0.0187 \\
& 1,000 & 0 & 0 & 0.00121 & 0.00592 \\
& $\sqrt{10,000}$ & 0 & 0 & 0 & 0.00170 \\
& 10,000 & 0 & 0 & 0 & 0 \\
\hline \multirow{2}{*}{0.50} & 1 & 0.119 & 0.438 & 1.29 & 3.20 \\
& $\sqrt{10}$ & 0.0463 & 0.211 & 0.780 & 2.30 \\
& 10 & 0.0159 & 0.0824 & 0.375 & 1.39 \\
& $\sqrt{100}$ & 0.00513 & 0.0283 & 0.146 & 0.667 \\
& 100 & 0.00154 & 0.00912 & 0.0503 & 0.260 \\
& $\sqrt{1,000}$ & 0 & 0.00275 & 0.0162 & 0.0895 \\
& 1,000 & 0 & 0 & 0.00489 & 0.0289 \\
& $\sqrt{10,000}$ & 0 & 0 & 0 & 0.00869 \\
& 10,000 & 0 & 0 & 0 & 0 \\
\hline \multirow{2}{*}{0.70} & 1 & 0.193 & 0.845 & 2.90 & 8.34 \\
& $\sqrt{10}$ & 0.0783 & 0.433 & 1.89 & 6.50 \\
& 10 & 0.0273 & 0.175 & 0.969 & 4.24 \\
& $\sqrt{100}$ & 0.00891 & 0.0612 & 0.392 & 2.17 \\
& 100 & 0.00278 & 0.0200 & 0.137 & 0.878 \\
& $\sqrt{1,000}$ & 0 & 0.00622 & 0.0447 & 0.307 \\
& 1,000 & 0 & 0 & 0.0139 & 0.100 \\
& $\sqrt{10,000}$ & 0 & 0 & 0 & 0.0312 \\
& 10,000 & 0 & 0 & 0 & 0 \\
\hline \hline
\end{tabular}

This may be recognized as the derivative of the logarithmic law. Indeed, integration of Eq. 4 at constant $t^{\prime}$ yields the expression

$J\left(t, t^{\prime}\right)=E_{0}^{-1}\left[1+\psi_{1}\left(t^{\prime^{-m}}+\alpha\right) t^{\prime^{n}} \ln t+f_{0}\left(t^{\prime}\right)\right]$

in which function $f_{0}\left(t^{\prime}\right)$ is an integration constant. So we see that the triple power law (Eq. 2) does have the desired asymptotic behavior for very short and very long load durations.

Integrating Eq. 2, we obtain the integrated form of the triple power law. It may be written in the form

$J\left(t, t^{\prime}\right)=\frac{1}{E_{0}}+\frac{\phi_{1}}{E_{0}}\left(t^{\prime^{-m}}+\alpha\right)\left[\left(t-t^{\prime}\right)^{n}-B\left(t, t^{\prime} ; n\right)\right]$

in which $1 / E_{0}$ is an integration constant that represents the asymptotic instantaneous deformation, and

$B\left(t, t^{\prime} ; n\right)=n \int_{\xi=0}^{t-t^{\prime}}\left[1-\left(\frac{t^{\prime}}{t^{\prime}+\xi}\right)^{n}\right] \xi^{n-1} d \xi, \quad \xi=t-t^{\prime} \ldots \ldots \ldots \ldots \ldots$

The last integral is a binomial integral, which can be evaluated in terms of elementary functions only for certain values of $n$; however, none of

\begin{tabular}{|c|c|c|c|c|}
\hline (7) & (8) & (9) & (10) & (11) \\
\hline $\begin{array}{l}1.72 \\
1.27 \\
0.834 \\
0.461 \\
0.208 \\
0.0783 \\
0.0264 \\
0.00837 \\
0.00240 \\
\end{array}$ & $\begin{array}{l}3.02 \\
2.43 \\
1.80 \\
1.18 \\
0.651 \\
0.294 \\
0.111 \\
0.0373 \\
0.0118 \\
\end{array}$ & $\begin{array}{l}4.99 \\
4.26 \\
3.43 \\
2.54 \\
1.66 \\
0.920 \\
0.415 \\
0.156 \\
0.0527 \\
\end{array}$ & $\begin{array}{l}7.92 \\
7.05 \\
6.02 \\
4.85 \\
3.59 \\
2.35 \\
1.30 \\
0.586 \\
0.221 \\
\end{array}$ & $\begin{array}{l}12.2 \\
11.2 \\
9.96 \\
8.51 \\
6.85 \\
5.07 \\
3.32 \\
1.84 \\
0.828\end{array}$ \\
\hline $\begin{array}{l}7.00 \\
5.68 \\
4.09 \\
2.47 \\
1.19 \\
0.463 \\
0.159 \\
0.0513 \\
0.0154 \\
\end{array}$ & $\begin{array}{l}14.2 \\
12.5 \\
10.1 \\
7.27 \\
4.38 \\
2.11 \\
0.824 \\
0.283 \\
0.0912 \\
\end{array}$ & $\begin{array}{c}27.5 \\
25.3 \\
22.1 \\
18.0 \\
12.9 \\
7.80 \\
3.75 \\
1.46 \\
0.503 \\
\end{array}$ & $\begin{array}{c}51.5 \\
48.9 \\
44.9 \\
39.4 \\
32.0 \\
23.0 \\
13.9 \\
6.67 \\
2.60 \\
\end{array}$ & $\begin{array}{l}94.7 \\
91.6 \\
86.9 \\
79.9 \\
70.0 \\
56.8 \\
40.9 \\
24.7 \\
11.9 \\
\end{array}$ \\
\hline $\begin{array}{l}21.4 \\
18.7 \\
14.5 \\
9.49 \\
4.86 \\
1.97 \\
0.686 \\
0.224 \\
0.0698\end{array}$ & $\begin{array}{c}51.8 \\
48.0 \\
41.8 \\
32.6 \\
21.2 \\
10.9 \\
4.40 \\
1.54 \\
0.501\end{array}$ & $\begin{array}{c}121 \\
116 \\
107 \\
93.5 \\
72.9 \\
47.5 \\
24.3 \\
9.86 \\
3.44\end{array}$ & $\begin{array}{l}276 \\
270 \\
259 \\
241 \\
209 \\
163 \\
106 \\
545 \\
22.1\end{array}$ & $\begin{array}{l}624 \\
617 \\
604 \\
581 \\
539 \\
469 \\
365 \\
238 \\
122\end{array}$ \\
\hline
\end{tabular}

these values is realistic for concrete. Nevertheless, it is possible to approximate this integral very accurately either by a truncated infinite series or by replacement of the integral with certain sums. This is described in Appendix I. Table 1 lists the values of this integral, from which interpolation is possible. Graphical plots of this integral are given in Fig. 2(a) and $(b)$.

\section{Verification by Test Data from Literature}

The triple power law is intended to model only the basic creep, i.e., creep at constant water content and temperature. Extensive comparisons have been made with the main test data available in the literature $(12,13,16-18,20,22,24,25)$. Fig. 3 shows as the solid lines the optimum fits of these data achieved with the triple power law (Eq. 6). The material parameter values are listed in the figures. The values indicated for the data of L'Hermite et al. are perhaps most typical for structural concretes.

The fits in Fig. 3 have been obtained by a nonlinear optimization procedure using Marquardt-Levenberg algorithm $(11,21)$. This algorithm was used to minimize the sum of squared deviations of the formula from the test data. The sampling points were placed at regular intervals on the 

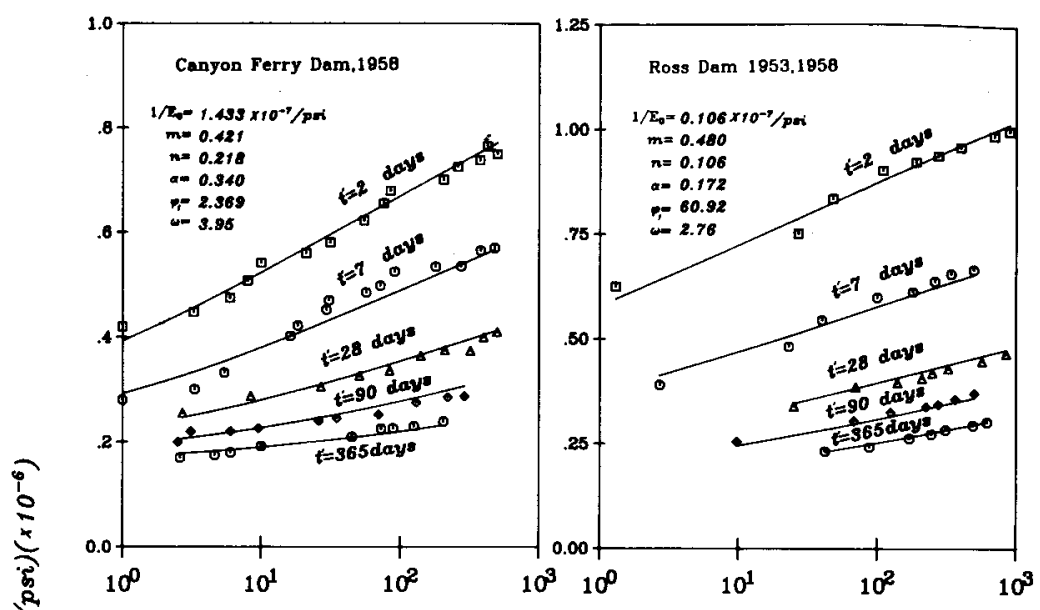

خ্خ

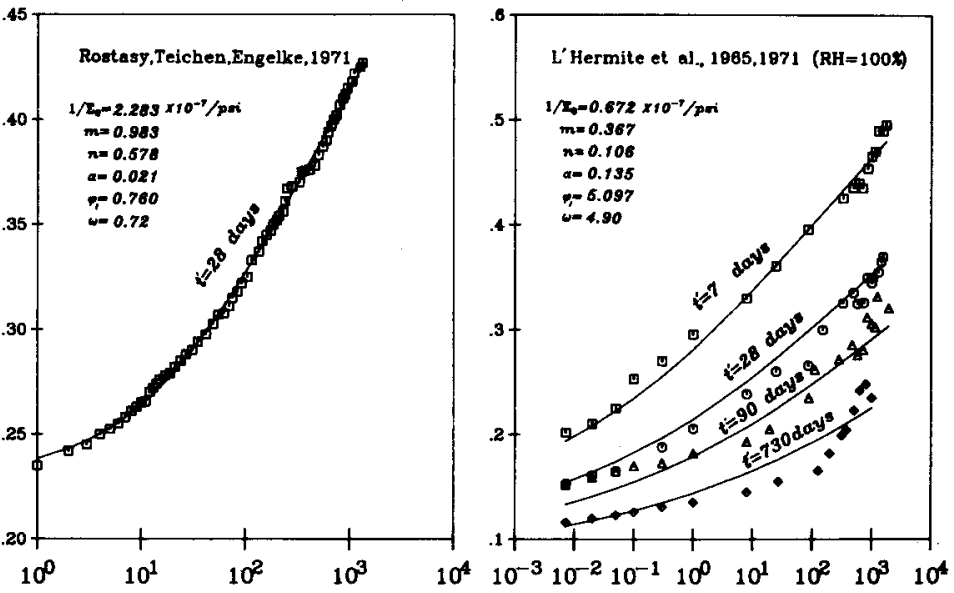

$t-t^{*}$ (days)

FIG. 3.-Fits of Creep Tests

measured creep curves in the logarithmic scale of load duration, and hand-smoothing of the measured data was used to partly suppress the measurement error. For more detail of the fitting procedure, see Ref. 10.

In the case of short-term creep data [e.g., Gamble and Thomass (16)], the optimum fits by the triple power law and the double power law are undistinguishable (see Table 2); however, for long-term data, the difference is significant. The pattern of gradual transition to straight lines in the logarithmic time scale is clearly apparent in the figures. The slopes of these straight lines are approximately the same as those obtained previously with the log-double power law (3). In that study it was found that the straight lines in the logarithmic time scale reduce the coefficient of variation of the deviations of the terminal slopes of the formula from the terminal slopes of test data (for all data sets combined) from the
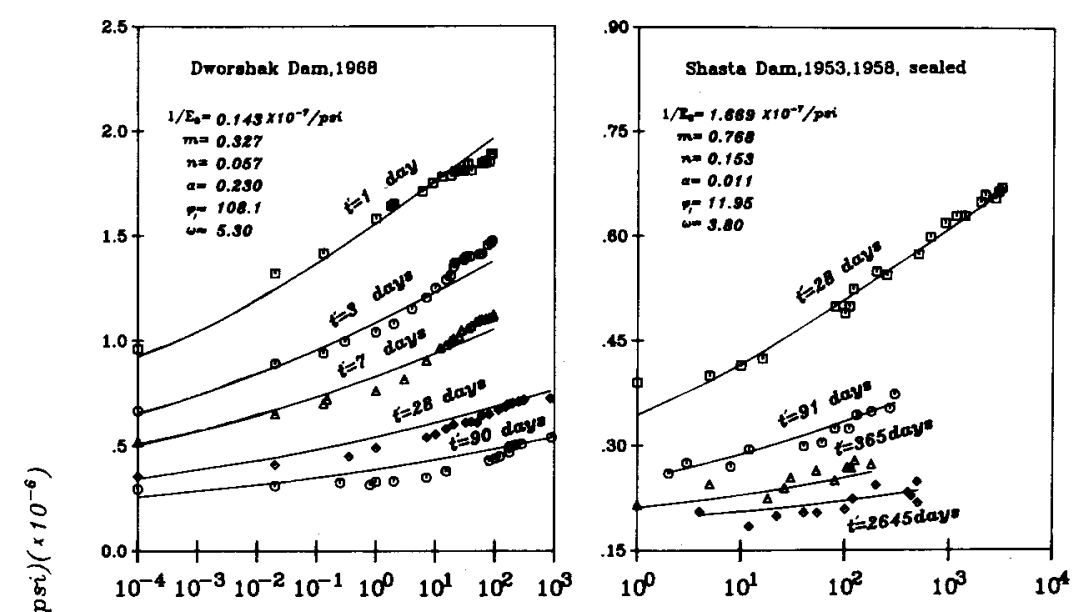

$$
\text { 豙 }
$$
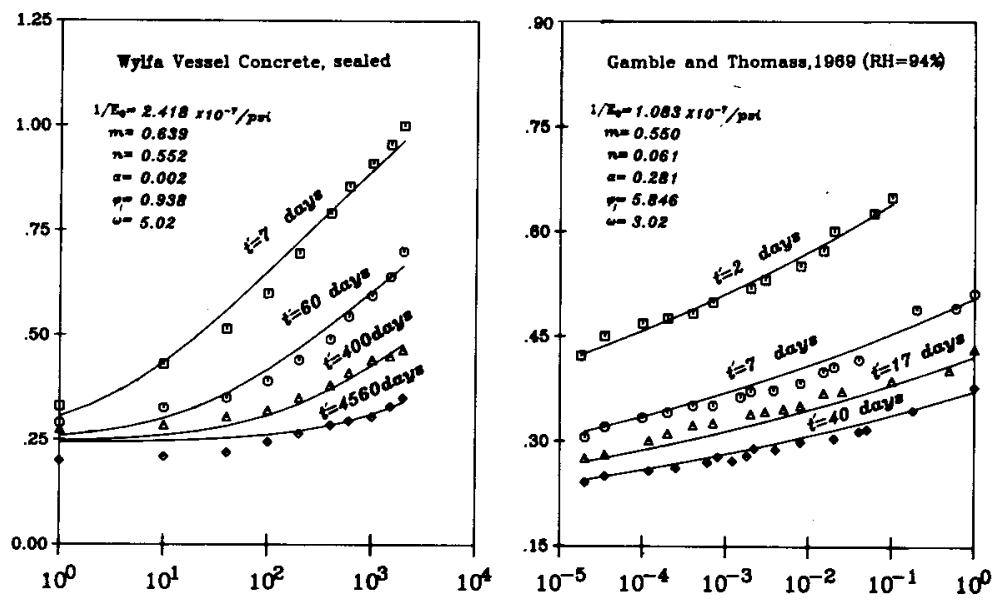

$t-t^{\cdot}$ (days)

\section{by Triple Power Law}

value of $34 \%$ for the double power law to $19 \%$. The same improvement in the representation of the final slopes of the creep curves is obtained with the present triple power law. This significantly reduces the error in extrapolations of creep data.

Compared to the previous log-double power law (3), the present formulation has the advantage that, in addition to the long-term response, the short-time creep for load durations below 0.1 day and down to the dynamic range (duration $0.001 \mathrm{~s}$ ) is also represented well. This is apparent from the curves in Fig. 3 , and is made possible by the fact that the triple power law asymptotically approaches the double power law with about the same parameter values as those found in the original data analysis $(6,10)$. Close fits of both the short- and long-time creep were also obtained with the previous formulation (3) in which the transition 
TABLE 2.-Coefficients of Variation for Devlations from Test Data

\begin{tabular}{|c|c|c|c|c|c|c|}
\hline \multirow[b]{2}{*}{$\begin{array}{l}\text { Data set } \\
\text { (1) }\end{array}$} & \multicolumn{2}{|l|}{$\omega_{1}$} & \multicolumn{2}{|l|}{$\omega_{2}$} & \multicolumn{2}{|l|}{$\omega$} \\
\hline & $\begin{array}{l}\text { TPL } \\
\text { (2) }\end{array}$ & $\begin{array}{l}\text { DPL } \\
\text { (3) }\end{array}$ & $\begin{array}{l}\text { TPL } \\
\text { (4) }\end{array}$ & $\begin{array}{c}\text { DPL } \\
\text { (5) }\end{array}$ & $\begin{array}{l}\text { TPL } \\
\text { (6) }\end{array}$ & $\begin{array}{c}\text { DPL } \\
\text { (7) }\end{array}$ \\
\hline 1. Canyon Ferry Dam & $6.27(3.36)$ & 10.20 & $9.39(5.56)$ & 15.80 & $3.95(4.75)$ & 4.60 \\
\hline 2. Ross Dam & 4.50 & 14.26 & 7.48 & 12.28 & 2.76 & 3.50 \\
\hline 3. Dworshak Dam & 5.12 & 8.43 & 7.43 & 12.28 & 5.30 & 5.46 \\
\hline 4. Rostasy et al. & - & - & - & - & 0.72 & 1.00 \\
\hline 5. L'Hermite et al. & 1.46 & 3.24 & 2.55 & 5.22 & 4.90 & 4.90 \\
\hline 6. Shasta Dam & 4.01 & 4.52 & 6.71 & 7.55 & 3.80 & 4.10 \\
\hline 7. Wylfa Vessel & 1.50 & 12.0 & 3.02 & 19.79 & 5.02 & 4.14 \\
\hline 8. Gamble-Thomass & 2.99 & 5.12 & 4.65 & 7.87 & 3.02 & 2.82 \\
\hline $\bar{\omega}_{1}, \bar{\omega}_{2}$ & $3.69(3.28)$ & 8.25 & $6.34(5.66)$ & 14.14 & $3.95(4.06)$ & 4.03 \\
\hline
\end{tabular}

TABLE 3.-Llst of Double Power Law Parameters

\begin{tabular}{l|c|c|c|l|c}
\hline \hline \multicolumn{1}{c|}{$\begin{array}{c}\text { Data set } \\
(1)\end{array}$} & $\begin{array}{c}1 / E_{0} \times 10^{7} \\
(2)\end{array}$ & $\begin{array}{c}m \\
(3)\end{array}$ & $\begin{array}{c}n \\
(4)\end{array}$ & $\begin{array}{c}\alpha \\
(5)\end{array}$ & $\begin{array}{c}\Psi_{1} \\
(6)\end{array}$ \\
\hline Canyon Ferry Dam & 0.543 & 0.322 & 0.115 & 0.10 & 7.267 \\
Ross Dam & 1.885 & 0.451 & 0.114 & 0.01 & 2.814 \\
Dworshak Dam & 1.076 & 0.353 & 0.058 & 0 & 13.51 \\
Rostasy et al. & 1.549 & 0.437 & 0.185 & 0.224 & 1.031 \\
L'Hermite et al. & 0.420 & 0.329 & 0.084 & 0.198 & 7.786 \\
Shasta Dam & 1.115 & 0.701 & 0.099 & 0.032 & 17.46 \\
Wylfa Vessel & 1.823 & 0.262 & 0.228 & 0 & 1.357 \\
Gamble-Thomass & 1.083 & 0.550 & 0.061 & 0.281 & 5.844 \\
\hline \hline
\end{tabular}

from the double power law to the logarithmic law was sudden, with a jump in curvature. Compared to that formulation, the present one has the advantage of smoothness, i.e., continuous curvature.

The method of calculation of the aforementioned coefficients of variation was the same as that described in detail in the previous work $(4,10)$.

\section{Divergence of Creep Cunves}

When creep recovery curves are calculated from the double power law by means of the principle of superposition, they may be sometimes obtained as non-monotonic. In the case of aging materials, such a behavior does not violate any fundamental law of thermodynamics (5). However, it is unclear whether non-monotonic recovery curves are indeed a true property of the material (they have sometimes been observed in experiments, but mostly unobserved), or whether they are caused merely by an error in the creep formula, or some neglected nonlinear effects, such as microcracking or viscoplastic flow. Therefore, until better experimental data becomes available, it seems preferable to avoid, if possible, creep formulas that yield non-monotonic recovery curves. Even if one objects to these arguments on the basis of inapplicability of the principle of superposition to creep recovery, creep formulas that admit non-monotonic recovery appear to have certain other disadvantages; e.g., they yield negative values of stress at the end of long-time relaxation curves calculated from the principle of superposition.
Non-monotonic recovery is obtained if the slope of the creep curve decreases with the age at loading, $t^{\prime}$, at fixed current age $t$. In other words, the creep curves should not diverge (5), i.e.

$\frac{\partial^{2} J}{\partial t \partial t^{\prime}} \geq 0 \quad$ (nondivergence)

The double power law has been found to violate this nondivergence condition when $t-t^{\prime}$ is long and $t^{\prime}$ is short $(5,10)$. Precisely, the nondivergence condition for the double power law is

$t-t^{\prime} \leq \frac{1-n}{m} t^{\prime}\left(1+\alpha t^{\prime^{m}}\right)$

Differentiating Eq. 2 with respect to $t^{\prime}$, we obtain the nondivergence condition for the triple power law:

$\left[1-\frac{n}{m}\left(1+\alpha t^{\prime m}\right)\right]\left(t-t^{\prime}\right) \leq \frac{1-n}{m}\left(1+\alpha t^{\prime^{\prime m}}\right) t^{\prime}$

of which Eq. 9 is a special case. The right-hand side of Eq. 10 is always positive. The bracketed expression on the left-hand side can be either positive or nonpositive. If it is nonpositive, Eq. 10 is always satisfied, which happens for some computations of the material parameter values from test data. If this bracketed expression is positive, divergence is avoided only for load durations satisfying the inequality

$t-t^{\prime} \leq \frac{(1-n)\left(1+\alpha t^{\prime m}\right) t^{\prime}}{m-n\left(1+\alpha t^{\prime m}\right)}$

It so happens that optimum data fits are often obtained for material parameter values for which the divergence time given by Eq. 11 is finite. Comparisons of the divergence times for the double power law and for the present triple power law are given in Table 4 for the optimum fits of various test data from the literature. Note that the time at the start of divergence is generally much longer for the triple power law, which represents an improvement. Also note that, for most test data, the optimum fits attainable under the condition of no divergence, i.e., the condition of nonpositiveness of the bracketed term on the left-hand side of Eq. 10, are often much worse than the optimum fits obtained without any restriction on the material parameter values.

Keeping the time at which divergence begins as long as possible is not the only desirable aspect of a creep formula. It is also desirable to minimize the distance by which the creep curves diverge apart after the start of divergence (this minimizes, in creep recovery predictions, the amount of reverse recovery). To quantify this property, we divide the scale of $\log t$ into equal time intervals, with 6 intervals/decade. We define as $\Delta_{i j}$ the excess of the vertical distance of two adjacent creep curves over the minimum distance between these two curves, occurring at the time at which the divergence begins. Subscript $j=1,2,3, \ldots N$ refers to the points at which the vertical distances are taken, and subscripts $i=1,2$, ... refer to various combinations of times $t$ ' for the various pairs of creep curves [see Fig. $4(a)$ and $4(b)$ ]. The values of $t^{\prime}$ were considered 
TABLE 4.-Elapsed Time Limits for Nondivergence, in Days

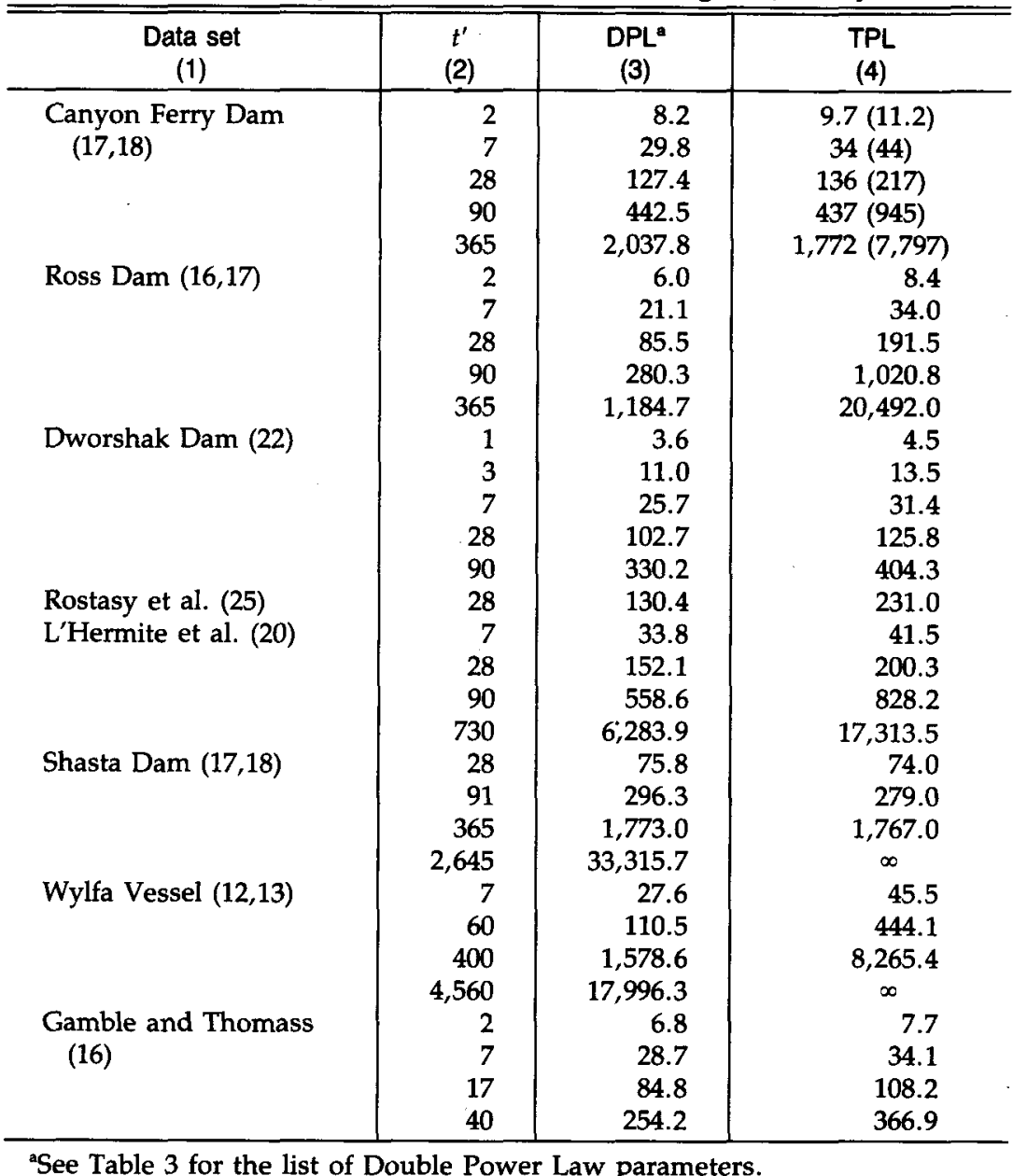

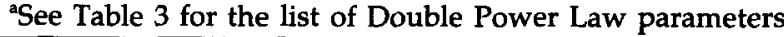

equally spaced in the $\log t^{\prime}$ scale, and all possible pairs of creep curves were considered in the calculation. Six values of $t^{\prime}$ were considered per decade in $\log t^{\prime}$. The values of $t^{\prime}$ ranged from one day to seven $\mathrm{yr}$, and the values of $t$ ranged from one second to many decades. With the foregoing definitions, the average distance by which the creep curves diverge may be characterized by one of the following two coefficients:

$\omega_{1}=\frac{\left(\sum_{i} \sum_{j} \frac{\left\langle\Delta_{i j}\right\rangle}{n}\right)}{\bar{J}} \quad \omega_{2}=\frac{\left(\sum_{i} \sum_{j} \frac{\left\langle\Delta_{i j}\right\rangle^{2}}{n}\right)^{1 / 2}}{\bar{J}}$

the first being a linear measure and the other a mean square measure. $\tilde{J}$ is the mean of all data points uniformly spaced in $\log \left(t-t^{\prime}\right)$ and $\log$
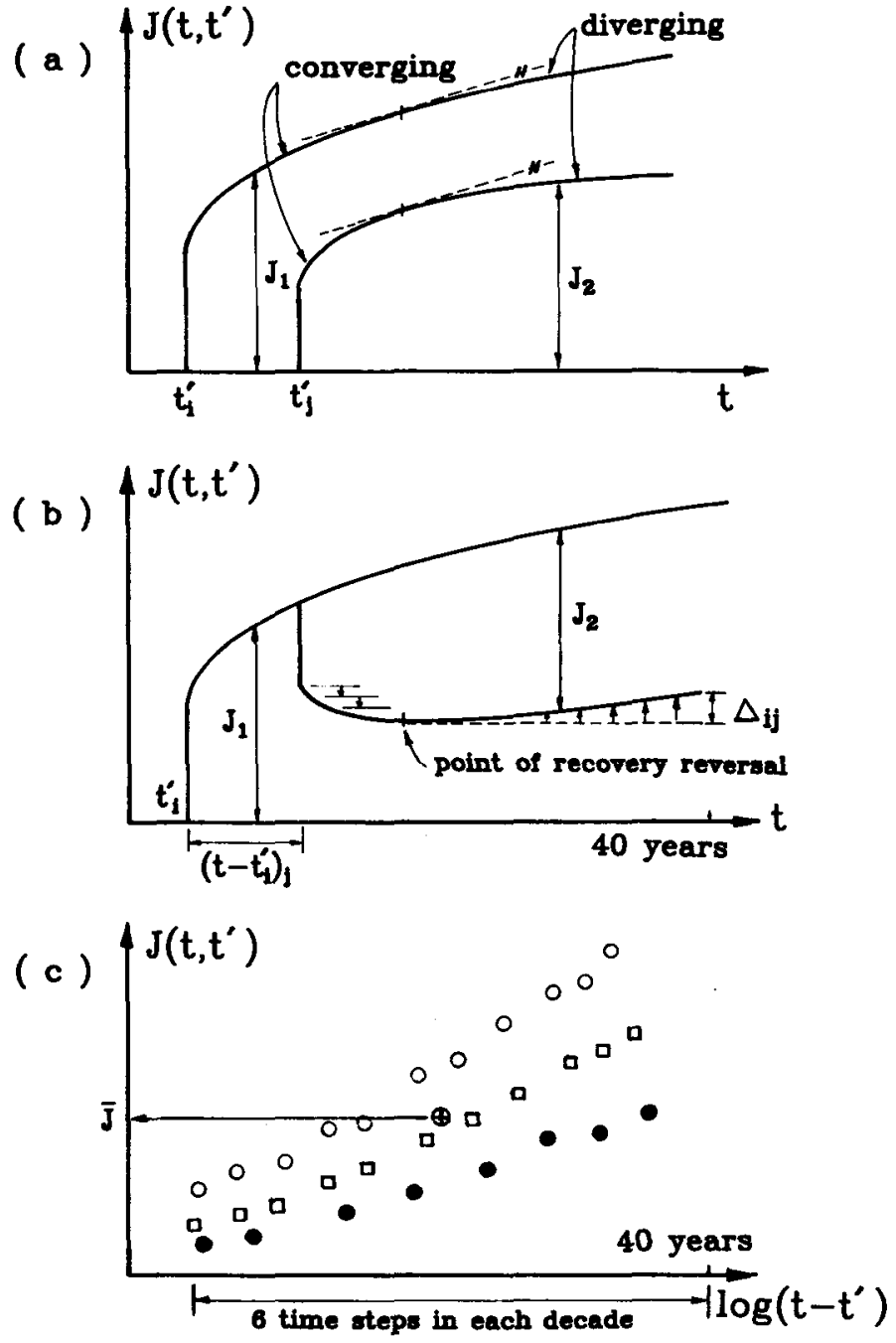

FIG. 4.-(a) Divergence of Creep Curves; (b) Non-Monotonic Recovery Curve Obtained by Principle of Superposition; (c) Mean Point of Data

$\left(t-t^{\prime}\right)$ scales [Fig. 4(c)]. The symbol of pointed brackets is defined by $\langle x\rangle=x$ if $x>0,\langle x\rangle=0$ if $x \leq 0$. The values of these coefficients for the optimum fits of individual test data from the literature by the triple power law have been combined into overall coefficients defined as

$\bar{\omega}_{1}=\frac{1}{M} \sum_{m=1} \omega_{1_{(m)}} \quad \bar{\omega}_{2}=\left(\frac{1}{M} \sum_{m=1}^{M} \omega_{2_{(m)}}^{2}\right)^{1 / 2}$

in which subscript $m=1,2, \ldots M$ refers to the individual data sets. The values of these coefficients are listed in Table 2 , for both the triple power 

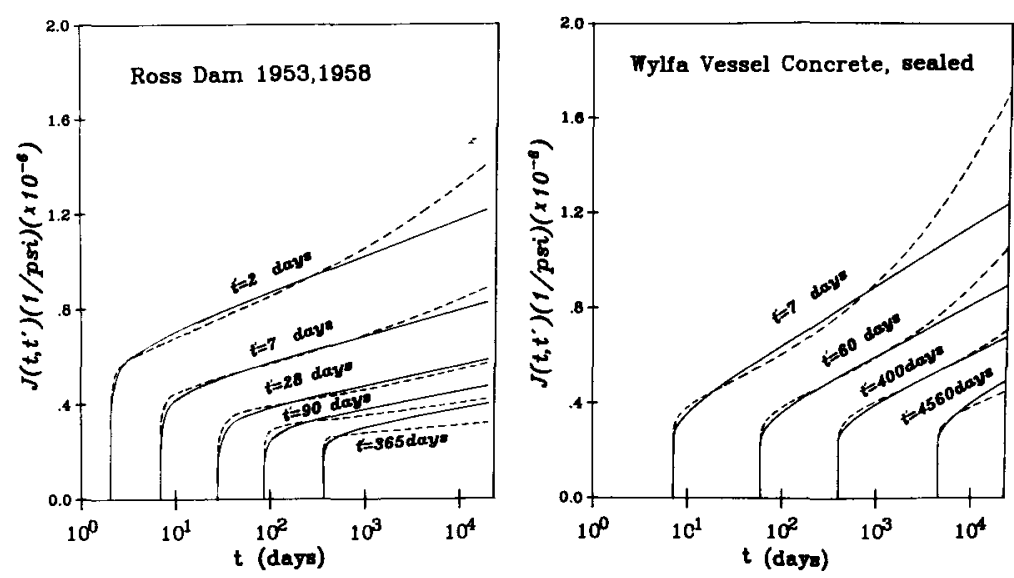

FIG. 5.-Curves Obtained by Fitting Triple Power Law (Solid Lines) and Double Power Law (Dashed Lines) to Test Data from Refs. 1, 2, 17 and 18

law and the double power law. We see that the amount of divergence is significantly reduced for the present formulation; for the double power law we have $\bar{\omega}_{1}=8.3 \%$ and $\bar{\omega}_{2}=14.1 \%$, while for the present triple power law we have $\bar{\omega}_{1}=3.7 \%$ and $\bar{\omega}_{2}=6.3 \%$. Fig. 5 clearly shows the early start of divergence of the double power law (dashed line), in contrast to the triple power law (solid lines).

Let us now examine the optimal fits under the restriction of nondivergence, i.e., $(m-n) t^{\prime-m}-n \alpha<0$ (based on Eq. 10). Noting that all material parameters must be positive, one obtains from this condition the inequality $n \geq m /\left(1+\alpha t^{\prime m}\right)$ for all $t^{\prime}$, i.e.

$n \geq \frac{m}{1+\alpha t_{\min }^{\prime m}}$

in which $t_{\min }^{\prime}$ denotes the minimum age at loading for which representation of creep properties is desired.

For the purpose of optimization of data fits, it is of interest to introduce an algebraic expression that automatically satisfies Eq. 14:

$n=\frac{m}{1+\alpha t_{\min }^{\prime m}}+\left(\frac{q}{1+s q}\right)^{2}$ or $n=\frac{m}{1+\alpha t_{\min }^{\prime m}}+s^{\prime}(1+\tanh q) \ldots$

The second term in these expressions corresponds to what is known in optimization as the penalty term, in which $q$ is any real number, and $s$ or $s^{\prime}$ is a suitably chosen coefficient based on fitting experience. The fact that the penalty term can never be negative ensures fulfillment of Eq. 14. This enables optimization of data fits without any inequality restriction, provided that the material parameters are considered as $E_{0}, \phi_{1}, m$, $\alpha$ and $q$, instead of $E_{0}, \phi_{1}, m, \alpha$ and $n$.

Fig. 6 shows one example of optimization of test data under the nondivergence condition. Note that the optimal fits clearly approach inclined straight lines for sufficiently long load durations. It is also obvious that the deviations from test data are higher than those when the di-

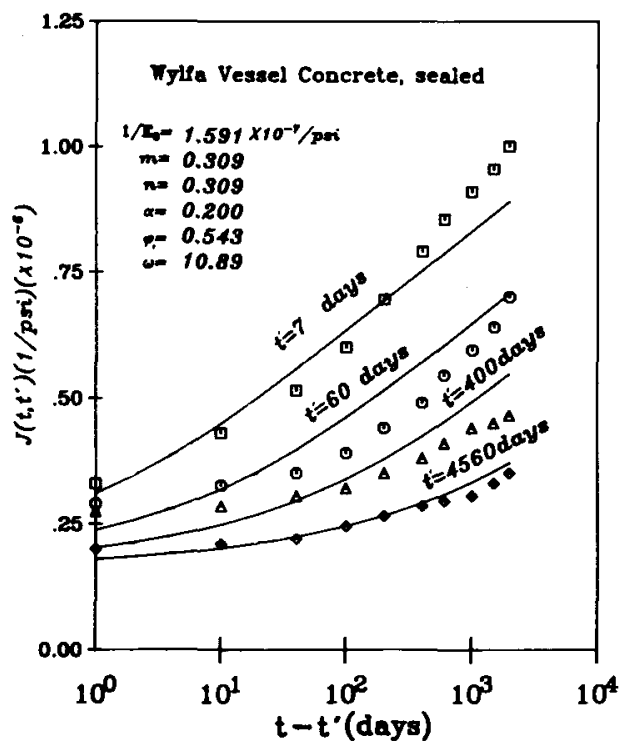

FIG. 6.-Fit of Wylfa Vessel Test Data under Nondivergence Constraint

vergence property is permitted; see Fig. 6. Another fit of Canyon Ferry Dam data $(m=0.375, n=0.136, \alpha=0.121)$ shows that a longer period of nondivergence and a smaller divergence magnitude can be achieved when the closeness of fit is sacrificed; see the values in parentheses in Tables 1 and 2 .

\section{Practical Prediction Model}

The capability of the creep formula to fit the test data confirms the correctness of the form of the formula, but does not mean that one can better predict creep in absence of any measurements, i.e., on the basis of design strength and composition. The prediction problem, typical in design practice, involves far greater uncertainty (7-10). It appears that the error in predicting material parameters is vastly greater than the error in the form of the creep formulas. Thus, for the prediction problem, no significant improvement can be expected from the present formulation, and none is achieved, as far as the overall coefficient of variation of deviations from measured data is concerned. Nevertheless, the more correct shape of the creep curves is an advantage even for predicted creep curves, since it achieves more realistic mutual relations of various creep values.

Extensive analysis of basic creep data $(12,13,16-18,20,22,24,25)$ indicated that the same values of material parameters as for the double power law $(7-10)$ can be used for the present formulation. This means, e.g., that the present formulation yields reasonable values also for the shorttime deformations, including the dynamic range. The ends of the creep curves are generally lower than for the double power law, which im- 
Setting $t_{0}=t^{\prime}$, and supposing that the interval $\left(0, \xi_{1}\right)$ is sufficiently small, we can rewrite Eq. 19 as

$B\left(t, t^{\prime}\right)=\frac{\xi_{1}}{2} b_{1}\left(\xi_{1}, t_{0}\right)+n \ln 10 \Delta(\log \xi) \sum_{i=1}^{N} c_{i} b\left(\xi_{i}, t_{0}\right)$

in which the step $\Delta(\log \xi)=\log \left(\xi_{i} / \xi_{i-1}\right)$ is constant. Trapezoidal rule is applied during the numerical integration $\left(c_{1}=c_{n}=0.5, c_{2}=\ldots=c_{N-1}\right.$ $=1$ ). Eight time steps/decade in the $\log t$-scale suffice for high accuracy. The accuracy of the integration may be checked by comparing the slope obtained numerically with that given by Eq. 21 . The first discrete time, $\xi_{1}$, is chosen as $0.0001 t^{\prime}$ (it was checked that $0.01 t^{\prime}$ yields about the same results). Using the approximation $\left[t^{\prime} /\left(t^{\prime}+\xi\right)\right]^{n} \simeq 1-\left(n \xi / t^{\prime}\right)$, the first term in Eq. 21 may be expressed as

$\frac{\xi_{1}}{2} b_{1}\left(\xi_{1}, t_{0}\right)=\frac{n \xi_{1}^{2}}{2 t_{0}}$

This approximation is very accurate if $n$ is small and $\xi_{1}<<t^{\prime}$.

Use of Dirichlet Series.-Integration is also possible by approximating the power functions in Eq. 7 by sums of exponentials, called Dirichlet series $(2,19)$. Within the interval (2) $0.3 \tau_{1} \leq t \leq 0.5 \tau_{M}$, one may use the approximation (2)

$t^{n}=\sum_{\mu=1}^{M+1} A_{\mu} e^{-t / \tau_{\mu}}$

and similarly

$\xi^{n-1}=\sum_{\mu=1}^{M+1} A_{\mu} e^{-\xi / \tau_{\mu}} \quad\left(t^{\prime}+\xi\right)^{-n}=\sum_{\mu=1}^{M+1} B_{\nu} e^{-\left(t^{\prime}+\xi\right) / \tau_{\nu}}$

Here, $A_{\mu}$ and $B_{v}$ are coefficients defined as (2)

$$
\begin{array}{ll}
\text { for } \nu, \mu=1,2, \ldots M-1: B_{\nu}, A_{\mu}=-\alpha(n) \tau_{\mu}^{r}, \quad \tau_{\mu}=10^{\mu-M}, \quad \tau_{M}=10^{\mu-1} \tau_{1} \\
\text { for } \nu, \mu=M \quad: \quad B_{m}, A_{M}=-1.2 \alpha(n) \tau_{N}^{r} \\
\text { for } v, \mu=M+1 & : B_{M+1}, A_{M+1}=\beta(n) \tau_{N}^{r}
\end{array}
$$

in which $r=$ exponent of the approximated power function $=n$ or $n-1$ or $-n$ for Eqs. 23 or $24, \tau_{M+1}=10^{6} \tau_{M}$; and $\alpha(n)$ and $\beta(n)$ are coefficients that have been determined by least-square fitting and are found in Table 1 of Ref. 2. Substituting the approximations in Eqs. 23 and 24 into Eq 7 , one can integrate and the result is

$$
\begin{aligned}
& B\left(t, t^{\prime}\right) \approx n \sum_{\mu=1}^{M+1} \frac{A_{\mu}}{\tau_{\mu}}\left[1-e^{-\left(t-t^{\prime}\right) / \tau_{\mu}}\right] \\
& +n t^{\prime \prime} \sum_{\mu=1}^{M+1} \sum_{\nu=1}^{M+1} \frac{A_{\mu} B_{v}}{T_{\mu \nu}} e^{-t^{\prime} / \tau_{\mu}}\left[1-e^{-T_{\mu \nu}\left(t-t^{\prime}\right)}\right]
\end{aligned}
$$

in which $\tau_{\mu \nu}=\left(1 / \tau_{\mu}\right)+\left(1 / \tau_{\nu}\right)$. This expression can be easily evaluated with a computer.

Asymptotic Approximation.-Setting $t=t^{\prime}+\xi$ in Eq. 7, we obtain
TABLE 5.-Function $f\left(t^{\prime}, n\right)$

\begin{tabular}{c|c|c|c|c|c|c|c}
\hline \hline & \multicolumn{7}{|c}{$n$} \\
\cline { 2 - 8 }$t^{\prime}$ days & $\begin{array}{c}0.06 \\
(1)\end{array}$ & $\begin{array}{c}0.10 \\
(2)\end{array}$ & $\begin{array}{c}0.150 \\
(4)\end{array}$ & $\begin{array}{c}0.20 \\
(5)\end{array}$ & $\begin{array}{c}0.25 \\
(6)\end{array}$ & $\begin{array}{c}0.30 \\
(7)\end{array}$ & $\begin{array}{c}0.50 \\
(8)\end{array}$ \\
\hline 1 & -0.994 & -0.984 & -0.965 & -0.939 & -0.921 & -0.851 & -0.729 \\
3.16 & -0.991 & -0.975 & -0.942 & -0.894 & -0.838 & -0.728 & -0.201 \\
10 & -0.983 & -0.949 & -0.876 & -0.760 & -0.600 & -0.354 & 1.50 \\
31.6 & -0.946 & -0.903 & -0.752 & -0.500 & -0.119 & 0.444 & 5.82 \\
100 & -0.917 & -0.830 & -0.549 & -0.051 & 0.751 & 2.00 & 16.10 \\
316 & -0.878 & -0.727 & -0.244 & 0.663 & 2.22 & 4.78 & 38.90 \\
1,000 & -0.829 & -0.586 & 0.196 & 1.75 & 4.58 & 9.48 & 87.2 \\
3,162 & -0.769 & - & - & - & - & - & - \\
\hline \hline
\end{tabular}

$B\left(t, t^{\prime} ; n\right)=n \int_{t^{\prime}}^{t}\left[1-\left(\frac{t^{\prime}}{t}\right)^{n}\right]\left(t-t^{\prime}\right)^{n-1} d t$

Differentiation then yields

$\frac{d B\left(t, t^{\prime} ; n\right)}{d t}=\left[1-\left(\frac{t^{\prime}}{t}\right)^{n}\right] n t^{n-1}\left(1-\frac{t^{\prime}}{t}\right)^{n-1}$

Here we may introduce the approximation $\left[1-\left(t^{\prime} / t\right)\right]^{n-1} \simeq 1-(n-1)$ $t^{\prime} / t$ for $t-t^{\prime}>>t^{\prime}$, upon which Eq. 28 becomes

$\frac{d B\left(t, t^{\prime} ; n\right)}{d t}=\left[1+\left(\frac{t^{\prime}}{t}\right)^{n}-(n-1) \frac{t^{\prime}}{t}+(n-1)\left(\frac{t^{\prime}}{t}\right)^{n+1}\right] n t^{n-1}$

Integration now yields

$B\left(t, t^{\prime} ; n\right)=f\left(t, t^{\prime} ; n\right)+\left[t^{n}-n t^{\prime n} \ln t-n t^{\prime} t^{n-1}-n(n-1) t^{\prime n+1} \frac{1}{t}\right]$

(for $t-t^{\prime}>>t^{\prime}$ )

in which $f\left(t^{\prime}, n\right)$ is a function tabulated in Table 5. This table has been calculated from the numerical values of $B\left(t, t^{\prime} ; n\right)$.

Remarks.- It is instructive to check other possible series approximations. Introducing $s=t^{\prime}+\psi \leq t$, Eq. 3 could be written as

$\dot{J}\left(s, t^{\prime}\right)=\frac{\psi_{1}}{E_{0}}\left(t^{\prime-m}+\alpha\right)\left(s-t^{\prime}\right)^{n-1}\left(\frac{t^{\prime}}{s}\right)^{n}$

Integration then yields

$J\left(t, t^{\prime}\right)=\frac{1}{E_{0}}+\frac{\Psi_{1}}{E_{0}}\left(t^{\prime-m}+\alpha\right) t^{\prime n} H\left(t, t^{\prime} ; n\right)$

in which $\psi_{1}=n \phi_{1}$ and

$H\left(t, t^{\prime} ; n\right)=\int_{s=t^{\prime}}^{t}\left(1-\frac{t^{\prime}}{s}\right)^{n-1} \frac{d s}{s}=\ln \frac{t}{t^{\prime}}+\sum_{k=1}^{\infty}\left(\begin{array}{c}n-1 \\ k\end{array}\right) \frac{(-1)^{k}}{k}\left[1-\left(\frac{t^{\prime}}{t}\right)^{k}\right]$

The radius of this series (i.e., $a_{i+1} / a_{i}$ ) must be less than unity as $i$ ap- 
proaches infinity, if the series should converge. However, here the ratio of two subsequent terms of the series is found to have the limit (for $i \rightarrow \infty$ ) of 1 , and, therefore, the series in Eq. 33 is divergent.

\section{Appendix II.-References}

1. Bažant, Z. P., "Mathematical Models for Creep and Shrinkage of Concrete," Chapter 7 in Creep and Shrinkage in Concrete Structures, Z. P. Bažant and F. H. Wittmann, eds., John Wiley \& Sons, London, U.K. 1982, pp. 163-256.

2. Bažant, Z. P., "Viscoelasticity of Porous Solidifying Material-Concrete," Journal of the Engineering Mechanics Division, ASCE, Vol. 103, No. EM6, 1977, pp. 1049-1067.

3. Bažant, Z. P., and Chern, J. C., "Log-Double Power Law for Concrete Creep," Report No. 83-11/679e, Center for Concrete and Geomaterials, The Technological Institute, Northwestern University, Evanston, Ill., 1983; American Concrete Institute Journal, Vol. 81, 1984, in press.

4. Bažant, Z. P., and Chern, J. C., "Double Power Logarithmic Law for Concrete Creep," Report No. 83-11/679d, Center for Concrete and Geomaterials, The Technological Institute, Northwestern University, Evanston, Ill., 1983; Cement and Concrete Research, Vol. 14, 1984, in press.

5. Bažant, Z. P., Kim, S. S., "Can the Creep Curves for Different Loading Ages Diverge?" Cement and Concrete Research, Vol. 8, 1978, pp. 601-612.

6. Bažant, Z. P., Osman, E., "Double Power Law for Basic Creep of Concrete," Materials and Structures (RILEM, Paris), Vol. 9, No. 49, 1976, pp. 3-11.

7. Bažant, Z. P., and Panula, L., "Practical Prediction of Time-Dependent Deformation of High Strength Concrete," Materials and Structures (RILEM, Paris), Vol. 15, 1984, in press (also Report, Center for Concrete and Geomaterials, Northwestern University, Evanston, Ill., 1983)

8. Bažant, Z. P., and Panula, L., "New Model for Practical Prediction of Creep and Shrinkage," Special Publication SP76, American Concrete Institute, Detroit, Mich., 1982, pp. 7-23.

9. Bažant, Z. P., and Panula, L., "Creep and Shrinkage Characterization for Analyzing Prestressed Concrete Structures," J. PCI, Vol. 25, No. 3, MayJune, 1980, pp. 86-122.

10. Bažant, Z. P., and Panula, L., "Practical Prediction of Time-Dependent Deformation of Concrete" Materials and Structures, Parts I and II: Vol 11, No. 65, 1978, pp. 307-328; Parts III and IV: Vol. 11, No. 66, 1978, pp. 415-434 and Parts V and VI: Vol. 12, No. 69, 1979, pp. 169-173.

11. Brown, K. M., "Derivative-Free Analogues of the Levenberg, Marquardt and Gauss Algorithms for Nonlinear Least Square Approximations," Philadelphia Scientific Center Technical Report No. 320-2994, IBM, 1970.

12. Browne, R. D., and Bamforth, P. P., "The Long Term Creep of the Wylfa P.V. Concrete for Loading Ages up to 12-1/2 years" 3rd International Conference on Structural Mechanics in Reactor Technology, Paper H 1/8, London, England, Sept., 1975.

13. Browne, R. D., and Blundell, R., "The Influence of Loading Age and Temperature on the Long Term Creep Behavior of Concrete in a Sealed, Moisture Stable State," Materials and Structures (RILEM, Paris), Vol. 2, 1969, pp. 133144

14. CEB-FIP Model Code for Concrete Structures, Commité Eurointernational du BétonFédération Internationale de la Précontrainte, CEB Bulletin No. 124/125-E, Paris, France, 1978.

15. Çinlar, E., Bažant, Z. P., and Osman, E., "Stochastic Process for Extrapolating Concrete Creep," Journal of the Engineering Mechanics Division, ASCE, Vol. 103, No. EM6, 1977, pp. 1069-1088.

16. Gamble, B. R., and Thomass, L. H., "The Creep of Concrete Subject to Varying Stress," Proceedings of the Australian Conference on the Mechanics of Structures and Materials, Adelaide, Australia, Paper No. 24, Aug., 1969.
17. Hanson, J. A., "A Ten-Year Study of Creep Properties of Concrete," Concrete Lab. Report No. SP-38, U.S. Department of the Interior, Bureau of Reclamation, Denver, Colo., July, 1953.

18. Harboe, E. M. et al., "A Comparison of the Instantaneous and the Sustained Modulus of Elasticity of Concrete," Concrete Lab. Report No. C-854, Division of Engineering Lab., U.S. Department of the Interior, Denver, Colo., March, 1985.

19. Hardy, G. M., and Riese, M., "The General Theory of Dirichlet Series," Cambridge Tracts in Mathematics and Mathematical Physics No. 18, Cambridge Univ. Press, Cambridge, Mass., 1915.

20. L'Hermite, R. G., Mamillan, M., and Lefèvre, $C$. "Nouveaux résultats de recherches sur la déformation et la rupture du béton," Annales de l'Institut Techn. du Bâtiment et des Travaux Publics, Vol. 18, No. 207-208, 1965, pp. Techn. du Bâtiment et des Travaux Publics, Vol. 18, No. 207-208, 1965, pp.
325-360; see also International Conference on the Structure of Concrete, Cement and Concrete Association, London, England, 1968, pp. 423-433.

21. Marquardt, D. W., "An Algorithm for Least Square Estimation of Non-Linear Parameters," Journal of SIAM, Vol. 2, 1963, pp. 431-441.

22. Pirtz, D., "Creep Characteristics of Mass Concrete for Dworshak Dam," Report No. 65-2, Structural Engineering Lab., University of California, Berkeley, Calif., Oct., 1968

23. "Prediction of Creep, Shrinkage and Temperature Effects in Concrete Structures," by ACI Committee 209, Subcommittee II, D. J. Carreira, Chmn., in "Designing for the Effects of Creep, Shrinkage and Temperature," ACI Special Publication SP-76, (Proceedings of A. Pauw Symposium held at the ACI Convention, Houston, Tex., 1978), American Concrete Institute, Detroit, Mich., 1982, pp. 193-300.

24. Ross, A. D., "Creep of Concrete under Variable Stress," American Concrete Institute Journal, Vol. 54, 1958, pp. 739-758.

25. Rostasy, F. S., Teichen, K. T., and Engelke, H., "Beitrag zur Klarung der Zusammenhanges von Kriechen und Relaxation bei Normal-Beton," Bericht, Amtliche Forschungs-und Materialprüfungsanstalt für das Bauwesen. OttoGraf-Institut, Universität Stuttgart, Strassenbau und Strassenverkehrstechnik, Heft 139, 1972.

26. Shank, J. R., "The Plastic Flow of Concrete," Bulletin No. 91, Ohio State Univ. Eng. Exp. Stn., 1935.

27. Wittmann, F. H., "Creep and Shrinkage Mechanisms," Chapter 6 in Creep and Shrinkage in Concrete Structures, Z. P. Bažant, and F. H. Wittmann, eds., John Wiley \& Sons, London, U.K., 1982, pp. 129-162. 